\title{
Oncology care providers' awareness and practice related to physical activity promotion for breast cancer survivors and barriers and facilitators to such promotion: a nationwide cross-sectional web-based survey
}

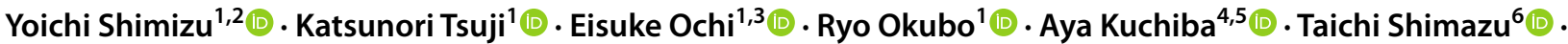 \\ Noriatsu Tatematsu ${ }^{7} \cdot$ Naomi Sakurai $^{8} \cdot$ Hiroji Iwata $^{9}(1) \cdot$ Yutaka J. Matsuoka $^{1,10}$
}

Received: 12 July 2021 / Accepted: 16 November 2021 / Published online: 1 December 2021

(c) The Author(s) 2021

\begin{abstract}
Purpose A known barrier to getting breast cancer survivors (BCSs) to engage in habitual exercise is a lack of information on recommended physical activity levels provided to them by oncology care providers (OCPs). However, the actual situation in Japan remains unclear. This study sought to clarify OCPs' awareness and practice related to Japan's physical activity recommendation for BCSs and to ascertain barriers to routine information provision.

Methods We conducted a web-based survey involving members of the Japanese Breast Cancer Society (JBCS) and the Japanese Association of Cancer Rehabilitation between Dec. 2018 and Feb. 2019.

Results Of 10,830 members, $1,029(9.5 \%)$ responded. Only $19.1 \%$ were aware of the details of the JBCS physical activity recommendation, and only $21.2 \%$ routinely provided physical activity information to BCSs. Factors related to being aware of the recommendation details were 1) availability of the guidelines, 2) experience reading relevant parts of the guidelines, and 3) involvement in multidisciplinary team case meetings. Barriers to routine information provision were 1) absence of perceived work responsibility, 2) underestimation of survivors' needs, 3) lack of resources, 4) lack of self-efficacy about the recommendation, and 5) poor knowledge of the recommendation.

Conclusions Only one fifth of the OCPs routinely provided physical activity information. Barriers to provision were poor awareness, self-efficacy, and attitudes and unavailable resources. The physical activity recommendation needs to be disseminated to all OCPs and an information delivery system needs to be established for BCSs to receive appropriate information and support to promote their engagement in habitual physical activity.
\end{abstract}

Keywords Physical activity $\cdot$ Breast cancer $\cdot$ Oncology care providers $\cdot$ Exercise implementation

\section{Introduction}

Maintaining high physical activity levels is known to play a role in extending the healthy lifespan of breast cancer survivors (BCSs) and in improving their health-related quality of life [1-5]. Accordingly, the American Cancer Society (ACS)/American Society of Clinical Oncology (ASCO) Breast Cancer Survivorship Guideline and the Japan Breast Cancer Society (JBCS) Clinical Practice Guidelines for systemic treatment of breast cancer strongly

Yutaka J. Matsuoka

matsuoka-psy@umin.ac.jp

Extended author information available on the last page of the article recommend that survivors maintain high physical activity levels [5-7]. The ACS/ASCO guideline recommends 150 min or more per week of moderate-intensity physical activity (e.g., moderate walking or light jogging sufficient to induce sweating) or 75 min or more per week of vigorous physical activity (e.g., jogging or resistance training) [6]. The JBCS guidelines recommend $60 \mathrm{~min}$ or more per week of moderate-to-vigorous intensity physical activity in addition to general physical activity in daily life $[5,7]$. Despite such recommendations, $54-67 \%$ of BCSs remain physically inactive [8-10].

One of the barriers to maintaining high physical activity levels that patients report is a lack of information on physical activity provided by their oncologist [11-13]. This is 
despite cancer survivors having shown a strong preference for receiving such information from their oncologist $[14,15]$. Several studies have reported that oncologists' recommendations on exercise, or in combination with other interventions, increased patients' physical activity levels [16-18], and yet most oncologists still do not recommend physical activity to their patients, for various reasons including lack of time, being unclear about specific exercises to recommend, concerns about the effectiveness of exercise, patient safety, and poor knowledge about exercise [19-21]. Therefore, multidisciplinary team members should share the role of discussing exercise recommendations with cancer survivors to increase their physical activity levels [21].

Taking a multidisciplinary team approach to promoting physical activity is also not enough, however. This is despite several studies reporting that most cancer survivors would prefer to receive physical activity counseling or information from a fitness expert or physical activity specialist associated with a cancer center together with input from their health practitioner (i.e., specialist nurse, physician, or oncologist) [21]. To date, the barriers and facilitators to multidisciplinary team members' routine provision of physical activity information have not been fully studied. Also, the amount of physical activity information that is actually provided by oncology care providers (OCPs) in Japan remains unclear. In order to assess the barriers and facilitators to OCPs systematically providing such information, in this study we used the Consolidated Framework for Implementation Research (CFIR), one of the most common frameworks for guiding systematic research that evaluates the process of implementing the delivery of health care [22-24].

We also considered OCPs' own high physical activity levels to be one of the facilitators to their routine provision of physical activity information. Some previous studies reported that OCPs with higher physical activity levels themselves tended to have a positive attitude to physical activity promotion and to provide more physical activity information to patients [19, 21, 25], whereas other studies reported no association between OCPs' own physical activity levels and their provision of physical activity information to patients [26]. Given the conflicting evidence, we examined this as a potential facilitating factor.

The purpose of this study was threefold: 1) to determine OCPs' awareness of the detailed contents of the JBCS physical activity recommendation, 2) to determine their routine provision of information about the JBCS physical activity recommendation to BCSs, and 3) to reveal the barriers and facilitators related to their awareness and provision.

\section{Methods}

\section{Participants and procedures}

We conducted a web-based self-report questionnaire survey using SurveyMonkey (SurveyMonkey, Palo Alto, CA) involving OCPs who were members of the JBCS $(n=9,996)$ or the Japanese Association of Cancer Rehabilitation (JACR, $n=834$ ). Between December 2018 and February 2019, we sent an e-mail containing information on the research prospectus and the questionnaire link to each member on the societies' mailing lists. The prospectus described the study's purpose and method and the method of consent (checking the "participation" box implied consent to participate), as well as contact information. To avoid duplicate submissions from a member of both societies included in the study, respondents were first asked if they had completed the questionnaire as a member of the other academic society and those who answered affirmatively were automatically restricted from answering further questions. To improve the response rate, we sent three reminders to all members listed. Those who regularly provided medical treatments or care to BCSs for over a 1 -year period and were aged $\geq 20$ years were included in the analysis. Those who could not respond to the self-reported questionnaire (written in Japanese) or did not answer any questions related to the study outcomes were excluded from the analysis.

\section{Survey items}

A literature review did not identify suitable tools with established reliability and validity for use in this study, so we developed an original questionnaire. We created the questionnaire items based on the results of a focus group interview with OCPs and a review of the literature using the CFIR. We also conducted cognitive checks with multidisciplinary research teams including oncologists who usually provide treatment or care for BCSs, rehabilitation therapists, oncology nurses, fitness trainers, BCSs, exercise physiologists, sports scientists, and psychiatrists.

The questionnaire consisted of 4 sections. Section 1 collected socio-demographic information including age, sex, occupation, whether they were a manager or not, facility background, years of experience in breast cancer care, and frequency of medical care for BCSs. Section 2 asked about awareness and practice related to the JBCS physical activity recommendation, which were the outcome measures. For the question about awareness of the contents of the recommendation, we asked participants to select one of four options that most closely aligned with their 
experience: "I know its details," "I may have heard about it, but I don't know its details," "I have heard of its existence," or "I have never heard of it." For the question about how often they inform BCSs about the benefits of physical activity in practice, they selected one of three options that most closely aligned with their experience: "I routinely explain the benefits of physical activity to BCSs," "I occasionally explain the benefits of physical activity to BCSs," or "I have never explained the benefits of physical activity to BCSs before."

Section 3 asked about possible factors related to awareness and practice (Table 1). We created survey items according to subdomains of the CFIR: 3 items on "intervention characteristics," 5 on "outer setting," 10 on "inner setting," 10 on "characteristics of individuals," and 3 on "process."

Section 4 asked participants about their own physical activity levels using the Japan Public Health Center-based prospective study-physical activity questionnaire-short form (JPHC-PAQ-Short) [27], which has been validated $[27,28]$. This 3 -item scale consist of "heavy physical work or strenuous exercise" ("none," "under $1 \mathrm{~h}$," and "1 h or more"), "walking and standing" ("under $1 \mathrm{~h}$, ," " $1-2 \mathrm{~h}$," and "3 h or more"), and "sedentary activity" ("3 h or less," "3-8 h," and "8 h or more"). OCPs' physical activity levels were assessed by calculating the amount of moderateto-vigorous physical activity (MVPA) according to the scale manual $[27,28]$ and whether these met the physical activity level recommended by Japan's Ministry of Health, Labour and Welfare [29]. We also asked participants to select 1 of 5 response options about their exercise habits in leisure time ("almost none" to "almost every day").

\section{Data analysis}

We calculated descriptive statistics for OCPs' awareness and practice related to the JBCS physical activity recommendation. Awareness of the recommendation was assessed as a binary variable according to whether or not they were aware of the details. The practice of providing the recommendation was assessed as a binary variable according to whether or not they regularly explained the benefits of physical activity to BCSs. To identify possible factors related to awareness and practice, we conducted logistic regression analysis with a backward elimination technique using each of the two dichotomous variables of awareness and practice as an outcome variable and with all relevant variables as explanatory variables.

All tests were two-tailed with a $p$ value $<0.05$ indicating statistical significance. All statistical analyses were performed using SAS ${ }^{\circledR}$ Ver.9.4 (SAS Institute Inc., Cary, $\mathrm{NC})$.

\section{Results}

Among the members of the JBCS, 912 (9.1\%) responded to the survey and $892(8.9 \%)$ answered the questions about awareness and practice related to the physical activity recommendation. The corresponding numbers for the JACR were $159(19.1 \%)$ and 137 (16.4\%). The total number of participants included in the analysis was 1029 (9.5\%) (Fig. 1).

\section{Participant characteristics}

Participant characteristics are summarized in Table 1. Overall, $54.6 \%$ of participants were male and the mean age was 48.0 (standard deviation: 9.8) years. The occupation of most of the participants was physician (70.6\%), followed by nurse (11.7\%) and rehabilitation therapist (11.9\%). Most had experience caring for BCSs for 5 years or more and were caring for BCSs 5 or more times per week.

\section{Participants' awareness and practice related to the JBCS physical activity recommendation}

Only $19.1 \%$ of participants knew the details of the JBCS physical activity recommendation, $48.6 \%$ had heard of it but did not know the details, and $20.1 \%$ had heard of it. In addition, only $21.2 \%$ routinely explained the benefits of physical activity to BCSs and $59.0 \%$ occasionally explained it (Fig. 2).

\section{Items created using the CFIR}

\section{Intervention characteristics}

Approximately half of the participants believed there was insufficient evidence for the effects of physical activity on breast cancer-related outcomes. Many participants felt efforts to promote physical exercise to BCSs to help them maintain high physical activity levels were too time-consuming and resource-consuming (Table 1).

\section{Outer setting}

Many participants (75\%) recognized that more than $60 \%$ of BCSs needed support around physical activity. Few participants (14\%) believed that more than $60 \%$ of BCSs are at high risk of health problems from performing MVPA. Only 9.8\% of the participants reported that their facilities work with other facilities to help BCSs maintain high physical activity levels. Only 15\% knew of any behavioral support 


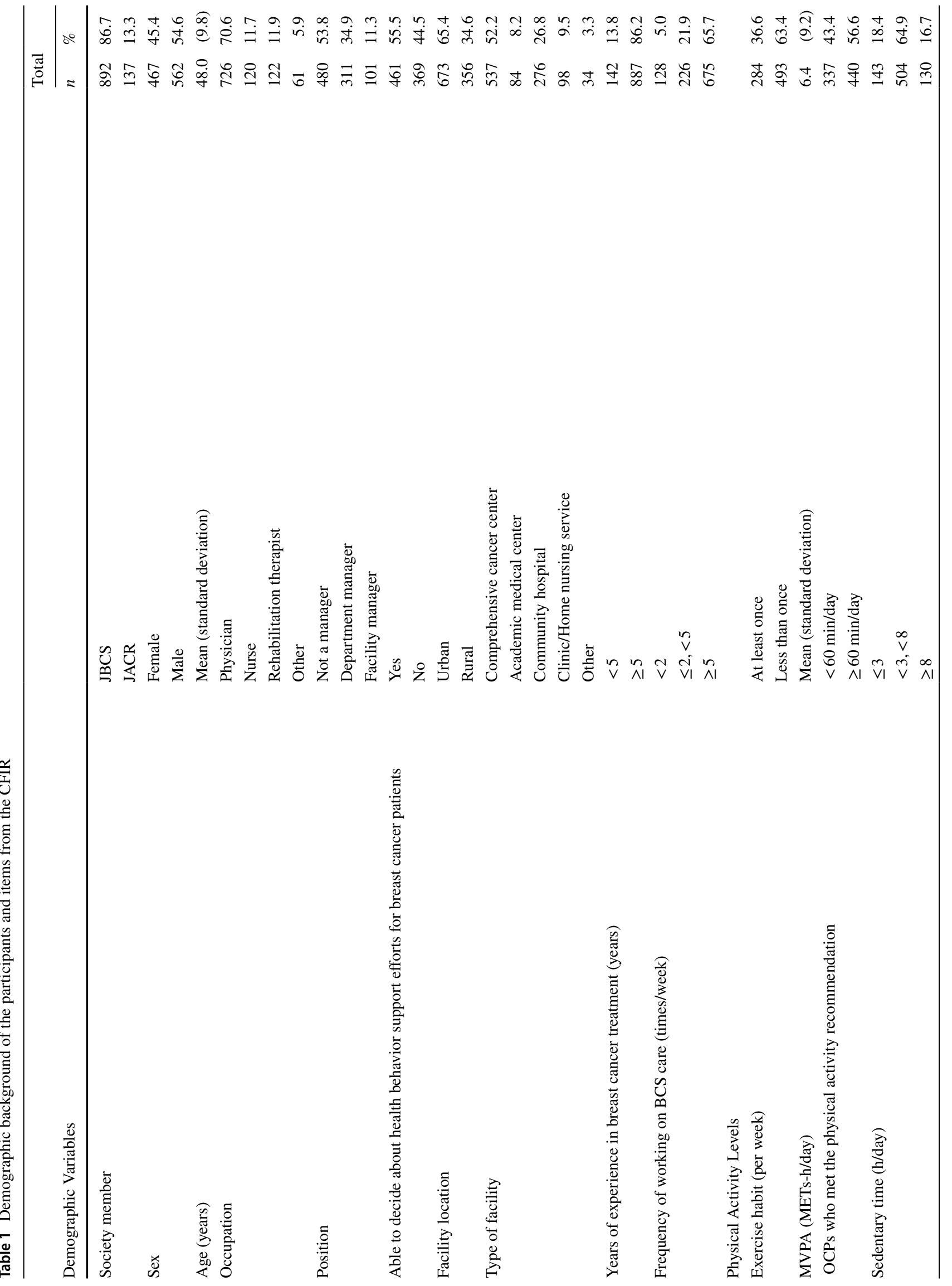




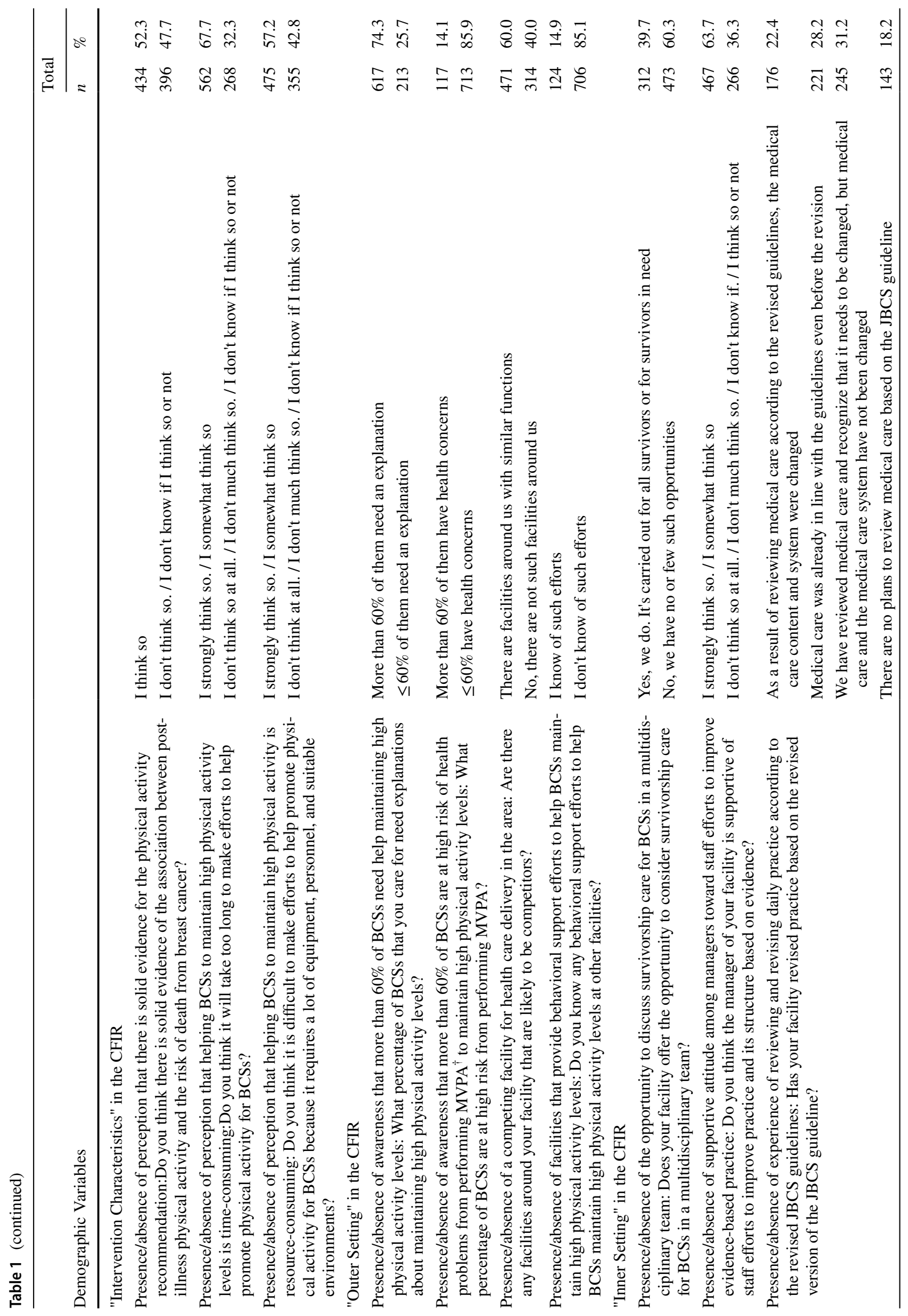




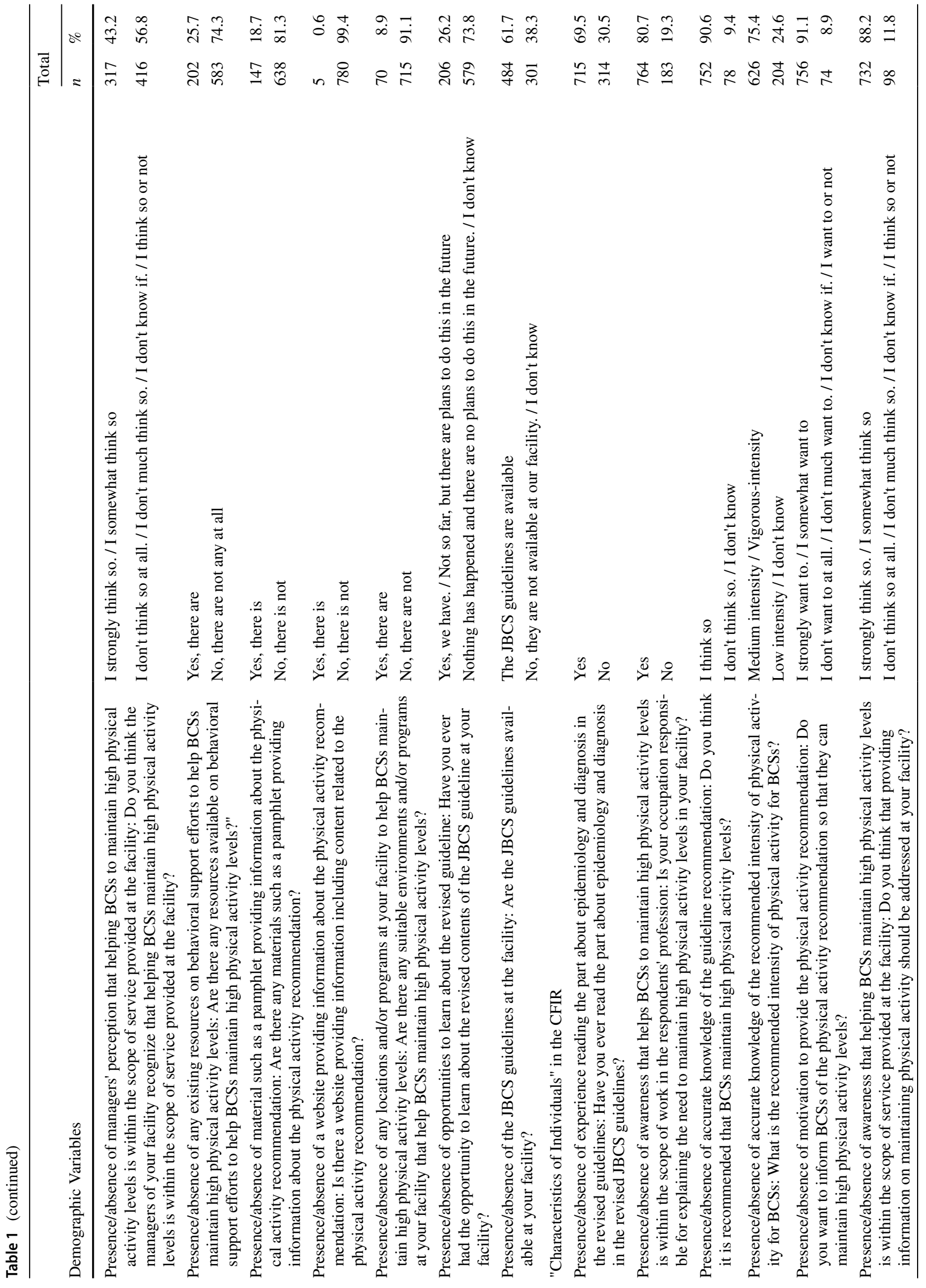




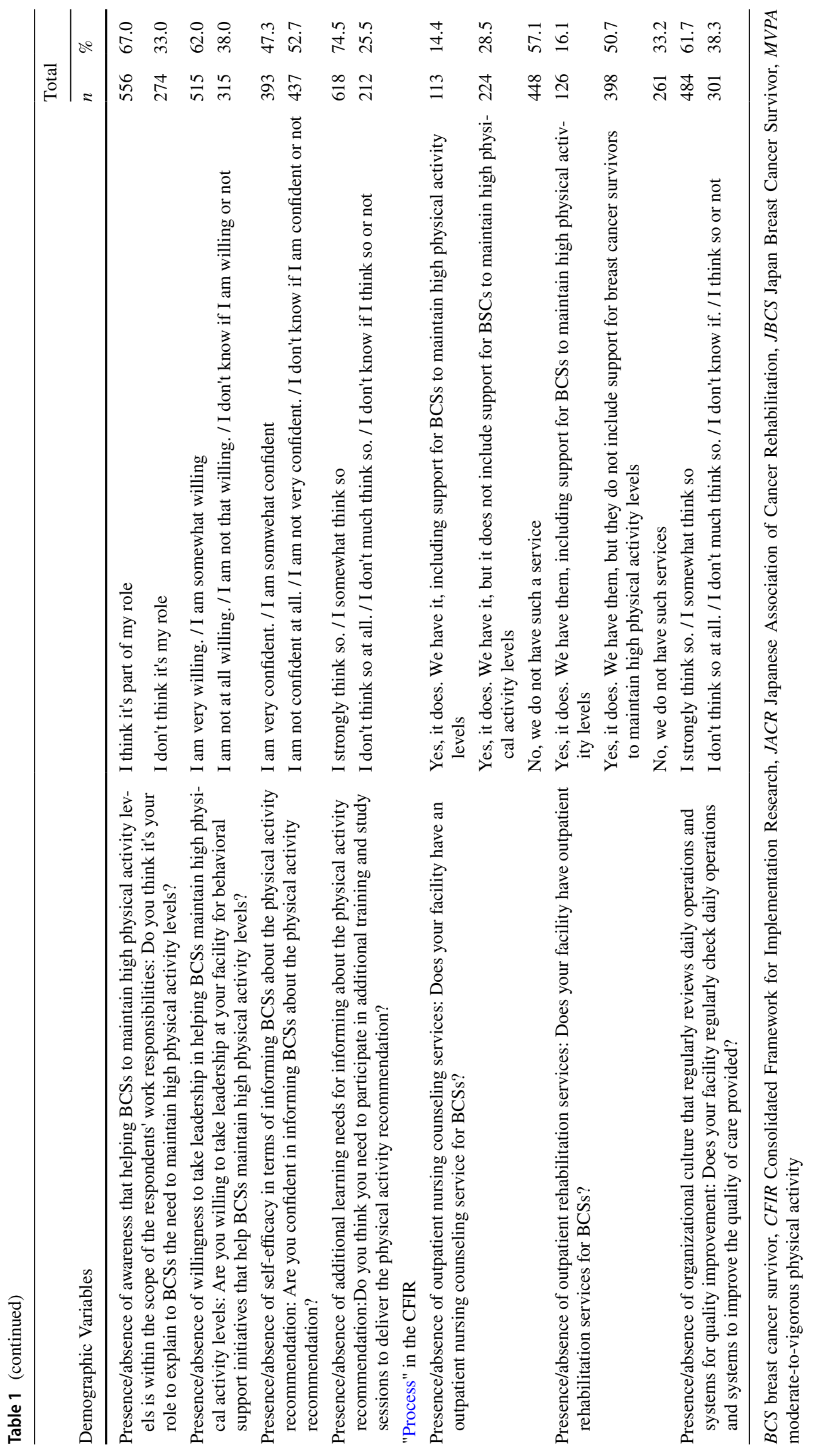


Fig. 1 Participants' recruiting flow diagram. JBCS: Japanese Breast Cancer Society, JACR: Japanese Association of Cancer Rehabilitation
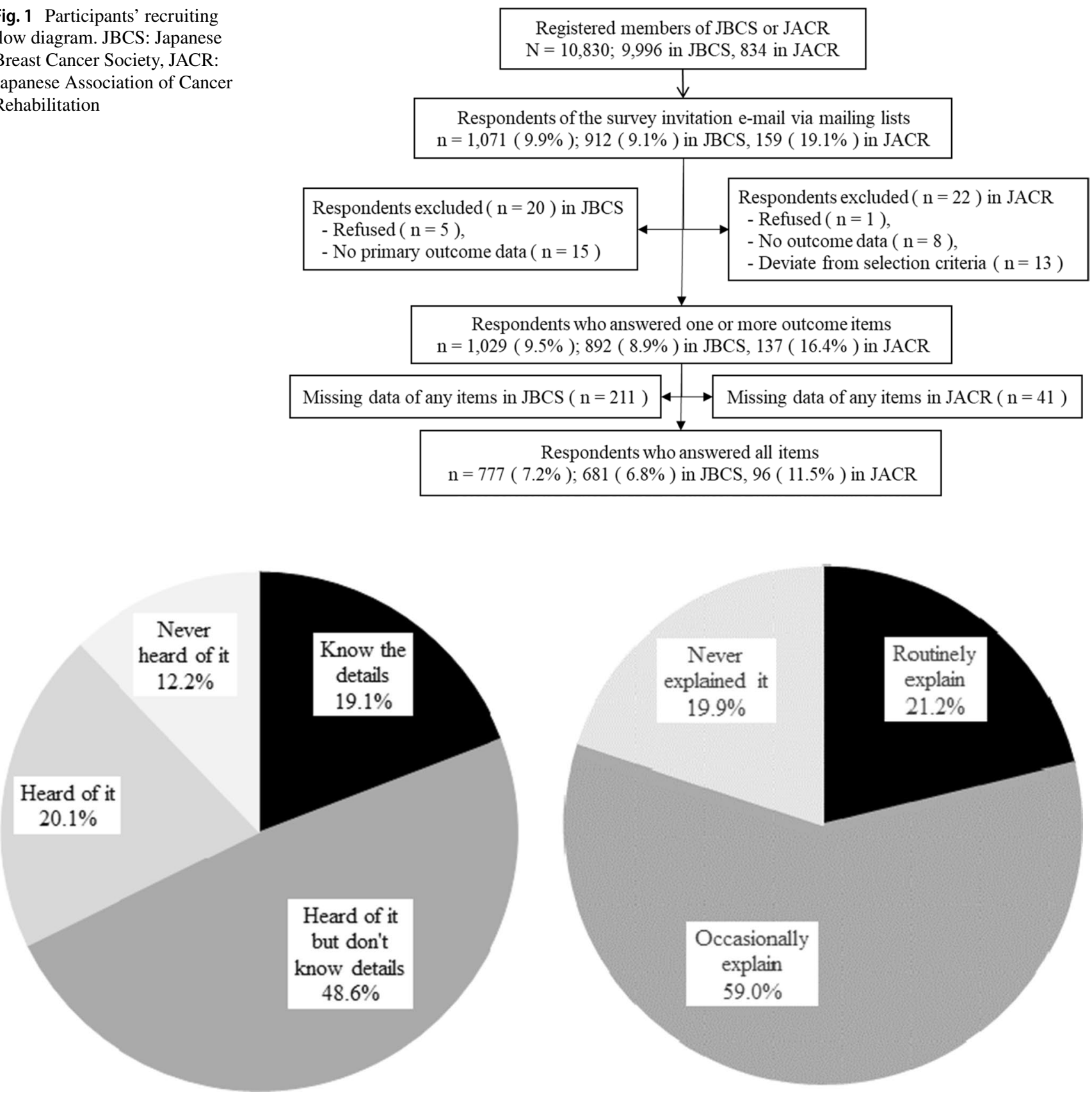

Fig. 2 Percentage of participants who were aware of and explained the contents of the physical activity recommendation in the Japan Breast Cancer Society Clinical Practice Guidelines. a. Percentage of participants who knew the contents of the physical activity recom-

efforts to maintain high physical activity for BCSs at other facilities (Table 1).

\section{Inner setting}

Approximately $40 \%$ of the participants had opportunities to consider survivorship care, including helping BCSs maintain high physical activity, in a multidisciplinary team. Half of mendation in the JBCS guidelines. b. Percentage of participants who routinely explain the benefits of maintaining high physical activity levels to breast cancer survivors

them had experience revising their daily practice in accordance with the revised JBCS guidelines or had confirmed their practice was in line with the revised guidelines. Only onequarter of them had opportunities to learn about the revised guidelines. Regarding the current resources available for BCSs to maintain physical activity levels at their facilities, $19 \%$ reported having some material such as a pamphlet providing information about the physical activity recommendation, 
$0.6 \%$ had a website providing information about the physical activity recommendation, and only $8.9 \%$ reported having any suitable environments or programs at their facility. Approximately $60 \%$ reported that the JBCS guidelines were available at their facility (Table 1).

\section{Characteristics of participants}

Approximately $70 \%$ had read the part about epidemiology and diagnosis in the revised JBCS guidelines. Overall, 91\% wanted to inform BCSs so that they could maintain high physical activity levels, and $80 \%$ recognized that explaining the need to maintain high physical activity levels was within the scope of work in their profession and also within the scope of services provided at their facilities. Approximately $60 \%$ were willing to take on leadership roles at their facilities for behavioral support initiatives to help BCSs maintain the recommended physical activity levels.

Approximately 90\% knew that it is recommended that BCSs maintain high physical activity levels. On the other hand, 25\% did not know the recommended exercise intensity. Half of the respondents were not confident in informing BCSs about the physical activity recommendation and $75 \%$ had additional learning needs about the recommendation (Table 1).

\section{Process}

Only $14.4 \%$ of participants reported that their facilities had outpatient nursing counseling services that included support for BCSs to maintain high physical activity levels versus $29 \%$ who reported that their facilities had outpatient nursing counseling services that did not include such support. Although $68 \%$ reported their facilities had outpatient rehabilitation services, only $16 \%$ reported that these included such support.

\section{Barriers and facilitators to participants' awareness and practice related to the physical activity recommendation}

The results of multivariate analysis (Table 2) showed that participants who tended to routinely explain the recommendation were characterized as follows: 1) perceived that helping BCSs to maintain high physical activity levels was within the scope of their profession's work (odds ratio [OR]: $6.1, p<0.01$ ); 2 ) perceived that more than $60 \%$ of BCSs need help maintaining high physical activity levels (OR: $2.4, p<0.01) ; 3$ ) were rehabilitation therapists (OR:2.2) or nurses (OR:1.7) $(p=0.03) ; 4)$ worked at facilities that had outpatient nursing counseling services that included support for BSCs to maintain high physical activity levels (OR: 2.1) or did not include such support (OR: 1.3) $(\mathrm{p}=0.03)$; 5) knew the details of the physical activity recommendation (OR: $1.8, p=0.01) ; 6$ ) perceived that there was solid evidence for the physical activity recommendation (OR: 1.6, $p=0.03)$; 7) worked at facilities that had any suitable environment or program to help BCSs maintain high physical activity levels (OR: 1.9, $p=0.03$ ); 8) had self-efficacy in terms of informing BCSs about the physical activity recommendation (OR: 1.6, $p=0.03$ ); 9) had accurate knowledge of the recommended level of physical activity (OR: 1.7, $p=0.03$ ); $10)$ met the physical activity recommendations themselves (OR: 1.6, $p=0.04$ ); and 11) perceived that helping BCSs to maintain high physical activity levels is within the scope of their work responsibilities (OR: $1.7, p=0.04$ ).

The following participants tended to know the details of the physical activity recommendation (Table 3): 1) had already read the part about epidemiology and diagnosis in the revised guidelines (OR: 7.4, $p<0.01)$; 2) had self-efficacy in terms of informing BCSs about the physical activity recommendation (OR: $2.9, p<0.01) ; 3$ ) perceived that helping BCSs to maintain high physical activity levels was within the scope of work in their profession (OR: 3.1, $p<0.01$ ); 4) worked at facilities that had outpatient nursing counseling services that included support BCSs to maintain high physical activity levels (OR: 2.0) or did not include such support (OR: 1.05) $(p=0.04) ; 5)$ perceived that there was solid evidence for the physical activity recommendation (OR: $1.8, p=0.01) ; 6$ ) had the opportunity to discuss survivorship care for BCSs in a multidisciplinary team (OR: 1.6, $p=0.02) ; 7$ ) worked at facilities where the JBCS guidelines were available (OR: 1.7, $p=0.04)$; and 8) had accurate knowledge of the recommended levels of physical activity (OR: 1.8, $p=0.048$ ).

\section{Discussion}

This is the first study to clarify OCPs' awareness and practice related to the physical activity recommendation for BCSs in the JBCS guidelines. Even though cancer survivors show a strong preference for receiving information about exercise behavior from their oncologist $[14,15]$, only $21.2 \%$ of the OCPs in the present study routinely tell BCSs about the physical activity recommendation.

Among the OCPs in this study, their perception about the scope of work responsibilities in their own profession was one of the most significant related factors in deciding whether or not to routinely explain the physical activity recommendation to BCSs. Notably, those who thought provision of physical activity information was not within the scope of work in their profession or within the scope of their own work responsibilities at their facility did not implement the recommendation. Therefore, an approach is needed that recognizes the provision of physical activity information as a routine part of care for BCSs. 
Table 2 Barriers and facilitators to oncology care providers' routinely explaining the physical activity recommendation in the JBCS revised guidelines

\begin{tabular}{|c|c|c|c|c|}
\hline Explanatory variables & & OR & $95 \% \mathrm{CI}$ & $p$ \\
\hline $\begin{array}{l}\text { Presence/absence of awareness that helps BCSs to maintain } \\
\text { high physical activity levels is within the scope of work in the } \\
\text { respondents' profession }\end{array}$ & $\begin{array}{l}\text { Presence } \\
\text { Absence }\end{array}$ & 6.1 & $\begin{array}{l}2.71-16.44 \\
\text { ref }\end{array}$ & $<0.001$ \\
\hline $\begin{array}{l}\text { Presence/absence of awareness that more than } 60 \% \text { of BCSs } \\
\text { need help maintaining high physical activity levels }\end{array}$ & $\begin{array}{l}\text { Presence } \\
\text { Absence }\end{array}$ & 2.4 & $\begin{array}{l}1.46-4.20 \\
\text { ref }\end{array}$ & 0.001 \\
\hline Occupation & $\begin{array}{l}\text { Physician } \\
\text { Nurse } \\
\text { Rehabilitation therapist } \\
\text { Other }\end{array}$ & $\begin{array}{l}1.7 \\
2.2 \\
1.0\end{array}$ & $\begin{array}{l}\text { ref } \\
0.89-3.01 \\
1.24-3.80 \\
0.27-3.40\end{array}$ & 0.031 \\
\hline Presence/absence of outpatient nursing counseling services & $\begin{array}{l}\text { Presence of outpatient nursing counseling ser- } \\
\text { vices, including support for maintaining high } \\
\text { physical activity for breast cancer survivors } \\
\text { Presence of outpatient nursing counseling } \\
\text { services, not including support for maintaining } \\
\text { high physical activity for breast cancer survivors } \\
\text { Absence of outpatient nursing counseling services }\end{array}$ & 1.3 & $0.82-1.93$ & 0.026 \\
\hline $\begin{array}{l}\text { Presence/absence of awareness about the details of the physical } \\
\text { activity recommendation }\end{array}$ & $\begin{array}{l}\text { Presence } \\
\text { Absence }\end{array}$ & 1.8 & $\begin{array}{l}1.14-2.80 \\
\text { ref }\end{array}$ & 0.011 \\
\hline $\begin{array}{l}\text { Presence/absence of perception that there is solid evidence for } \\
\text { the physical activity recommendation }\end{array}$ & $\begin{array}{l}\text { Presence } \\
\text { Absence }\end{array}$ & 1.6 & $\begin{array}{l}1.06-2.45 \\
\text { ref }\end{array}$ & 0.026 \\
\hline $\begin{array}{l}\text { Presence/absence of any locations and/or programs at your facil- } \\
\text { ity to help BCSs maintain high physical activity levels }\end{array}$ & $\begin{array}{l}\text { Presence } \\
\text { Absence }\end{array}$ & 1.9 & $\begin{array}{l}1.05-3.52 \\
\text { ref }\end{array}$ & 0.032 \\
\hline $\begin{array}{l}\text { Presence/absence of self-efficacy in terms of informing BCSs } \\
\text { about the physical activity recommendation }\end{array}$ & $\begin{array}{l}\text { Presence } \\
\text { Absence }\end{array}$ & 1.6 & $\begin{array}{l}1.05-2.39 \\
\text { ref }\end{array}$ & 0.029 \\
\hline $\begin{array}{l}\text { Presence/absence of accurate knowledge of the recommended } \\
\text { intensity of physical activity for BCSs }\end{array}$ & $\begin{array}{l}\text { Presence } \\
\text { Absence }\end{array}$ & 1.7 & $\begin{array}{l}1.06-2.95 \\
\text { ref }\end{array}$ & 0.033 \\
\hline OCPs who met the physical activity recommendations & $\begin{array}{l}<60 \mathrm{~min} / \text { day } \\
\geq 60 \mathrm{~min} / \text { day }\end{array}$ & 1.6 & $\begin{array}{l}1.02-2.48 \\
\text { ref }\end{array}$ & 0.039 \\
\hline $\begin{array}{l}\text { Presence/absence of awareness that helping BCSs to maintain } \\
\text { high physical activity levels is within the scope of the respond- } \\
\text { ents' work responsibilities }\end{array}$ & $\begin{array}{l}\text { Presence } \\
\text { Absence }\end{array}$ & 1.7 & $\begin{array}{l}1.03-2.86 \\
\text { ref }\end{array}$ & 0.041 \\
\hline
\end{tabular}

Logistic regression analysis with backward elimination $(p<0.05) ; R 2=0.17$, modified $R 2=0.26 \mathrm{c}$ statistics $=0.78 J B C S$ Japan Breast Cancer Survivor, JACR Japanese Association of Cancer Rehabilitation, BCS Breast Cancer Survivor, CFIR Consolidated Framework for Implementation Research, MVPA Moderate to vigorous physical activity, $O R$ odds ratio, $C i$ confidence interval, ref reference

OCPs who did not recognize that more than $60 \%$ of BCSs need help maintaining high physical activity levels tended not to routinely explain the physical activity recommendation. We chose to use the proportion of $60 \%$ in our questionnaire item given that 54-67\% of American BCSs do not meet the recommended physical activity levels [8-10]. We used overseas data in this case because there are no such data available for Japan other than currently unpublished data in a study that we conducted and will report on shortly [30]. Clearly, it is important to inform OCPs that there are many BCSs who potentially need help in maintaining high physical activity levels because they do not meet the JBCS recommendation.

OCPs who worked at facilities with available resources tended to routinely explain the physical activity recommendation more than those who worked at facilities without such resources. On the other hand, $68 \%$ perceived provision of the physical activity recommendation as timeconsuming and 57\% perceived it as resource-consuming. Thus, lack of time and available resources are barriers to OCPs routinely explaining the recommendation. This result is similar to that of previous studies $[19,21]$. Rehabilitation therapists who responded to our questionnaire tended to explain about the physical activity recommendation more than other OCPs, yet only $16 \%$ of their institutions had outpatient rehabilitation services to help BCSs maintain high physical activity levels. Also, $29 \%$ of our respondents reported that their facilities had outpatient nursing counseling services that did not include support for BCSs to maintain high physical activity levels and $51 \%$ reported that their facilities had outpatient 
Table 3 Barriers and facilitators to oncology care providers' awareness of the details of the physical activity recommendation of the JBCS revised guidelines

\begin{tabular}{|c|c|c|c|c|}
\hline \multicolumn{2}{|l|}{ Explanatory variables } & \multirow{2}{*}{ Ors } & \multirow{2}{*}{$\begin{array}{l}95 \% \text { Cis } \\
\begin{array}{l}3.52-18.2 \\
\text { ref }\end{array}\end{array}$} & \multirow{2}{*}{$\frac{p}{<.0001}$} \\
\hline $\begin{array}{l}\text { Presence/absence of experience reading the part about epidemi- } \\
\text { ology and diagnosis in the revised guidelines }\end{array}$ & $\begin{array}{l}\text { Presence } \\
\text { Absence }\end{array}$ & & & \\
\hline $\begin{array}{l}\text { Presence/absence of self-efficacy in terms of informing BCSs } \\
\text { about the physical activity recommendation }\end{array}$ & $\begin{array}{l}\text { Presence } \\
\text { Absence }\end{array}$ & 2.9 & $\begin{array}{l}1.88-4.59 \\
\text { ref }\end{array}$ & $<.0001$ \\
\hline $\begin{array}{l}\text { Presence/absence of awareness that helps BCSs to maintain } \\
\text { high physical activity levels is within the scope of work in the } \\
\text { respondents' profession }\end{array}$ & $\begin{array}{l}\text { Presence } \\
\text { Absence }\end{array}$ & 3.1 & $\begin{array}{l}1.47-7.39 \\
\text { ref }\end{array}$ & 0.005 \\
\hline $\begin{array}{l}\text { Presence/absence of perception that there is solid evidence for } \\
\text { the physical activity recommendation }\end{array}$ & $\begin{array}{l}\text { Presence } \\
\text { Absence }\end{array}$ & 1.8 & $\begin{array}{l}1.13-2.88 \\
\text { ref }\end{array}$ & 0.015 \\
\hline $\begin{array}{l}\text { Presence/absence of the opportunity to discuss survivorship } \\
\text { care for BCSs in a multidisciplinary team }\end{array}$ & $\begin{array}{l}\text { Presence } \\
\text { Absence }\end{array}$ & 1.6 & $\begin{array}{l}1.07-2.47 \\
\text { ref }\end{array}$ & 0.023 \\
\hline Presence/absence of the JBCS guidelines at the facility & $\begin{array}{l}\text { Presence } \\
\text { Absence }\end{array}$ & 1.7 & $\begin{array}{l}1.04-2.88 \\
\text { ref }\end{array}$ & 0.037 \\
\hline \multirow[t]{3}{*}{ Presence/absence of outpatient nursing counseling services } & $\begin{array}{l}\text { Presence of outpatient nursing counseling ser- } \\
\text { vices, including support for maintaining high } \\
\text { physical activity for breast cancer survivors }\end{array}$ & 2.0 & $1.14-3.57$ & 0.042 \\
\hline & $\begin{array}{l}\text { Presence of outpatient nursing counseling } \\
\text { services, not including support for maintaining } \\
\text { high physical activity for breast cancer survivors }\end{array}$ & 1.05 & $0.64-1.68$ & \\
\hline & Absence of outpatient nursing counseling services & & ref & \\
\hline $\begin{array}{l}\text { Presence/absence of accurate knowledge of the recommended } \\
\text { intensity of physical activity for BCSs }\end{array}$ & $\begin{array}{l}\text { Presence } \\
\text { Absence }\end{array}$ & 1.8 & $\begin{array}{l}1.02-3.26 \\
\text { ref }\end{array}$ & 0.048 \\
\hline
\end{tabular}

Logistic regression analysis with backward elimination $(p<0.05) . R 2=0.17$, modified $R 2=0.28$, c statistics $=0.81$. JBCS Japan Breast Cancer Survivor, JACR Japanese Association of Cancer Rehabilitation, BCS Breast Cancer Survivor, CFIR Consolidated Framework for Implementation Research, MVPA Moderate to vigorous physical activity, $O R$ odds ratio, $C i$ confidence interval, ref reference

rehabilitation services that did not include such support. There might be potential for these facilities to offer outpatient nursing and rehabilitation services that include such support. As only $9.8 \%$ of respondents answered that they are currently cooperating with other facilities in the area, promoting such collaboration may be an option to compensate for the lack of available resources. Proposing specific exercise programs to BCSs will likely be difficult in practice due to limited time and resources. To help address this, we have developed a homebased exercise program for BCSs that does not require the use of special tools and can be completed in a short time [31, 32].

In this study, self-efficacy was one of the most significant facilitators in the routine provision of the physical activity recommendation. This is consistent with the suggestion by Hardcastle et al. that increasing OCPs' confidence in physical activity promotion may improve their physical activity promotion behavior [25]. However, approximately half of our respondents did not have self-efficacy and around $75 \%$ wanted additional training and study sessions. We suggest that all OCPs be told specifically about the recommendation, so as to provide them the necessary knowledge and skills to implement the recommendation and thereby improve efficacy expectation $[33,34]$. On the other hand, it is also important to consider the outcome expectation. About half of respondents thought there was insufficient evidence for the physical activity recommendation. In the free description section of our questionnaire, some OCPs stated that it was not clear what kind of physical activity should be specifically recommended. Both in this study and a previous study by Park et al. [19], barriers to recommending exercise for cancer survivors were concerns about the effectiveness of exercise and perceived unclear recommendations. Because it is not clear exactly what types of physical activity programs are efficacious and efficient [19, 35], further research is warranted. Furthermore, most of the evidence available on physical activity originates from Europe and the USA [1-5], and as far as we know, there have been no previous studies concerning Japanese BCSs. It is known that physique and lifestyle, including physical activity levels, differ between Japanese and Western populations [36], and there are also racial differences in the risk of developing breast cancer [37] and in the outcomes for breast cancer [38]. Therefore, further research involving Japanese BCSs is needed.

Factors related to provision of the physical activity recommendation were awareness of its details and accurate knowledge of the recommended physical activity levels. This is similar to a previous finding that one of the most significant barriers to exercise discussion was OCPs' insufficient knowledge [21]. Factors related to being aware of the details of 
the physical activity recommendation were the same as some of the related factors for provision of the recommendation. Besides these common factors, the related factors of being aware of the recommendation details were 1) availability of the JBCS guidelines at the facility, 2) experience reading the relevant part in the revised guidelines, and 3) opportunity to discuss survivorship care in a multidisciplinary team. Given related factor 2), it will be important to promote the revised guidelines in collaboration with academic societies. Discussing survivorship care in a multidisciplinary team is thought to encourage understanding of the relevant evidence and guidelines, and we suggest offering OCPs such opportunities. Furthermore, bivariate analysis showed that experience of reviewing and revising daily practice in accordance with the revised JBCS guidelines tended to be a facilitator to awareness of the recommendation details (Table 3), so we also recommend creating a culture that confirms daily practice based on the evidence provided in the guidelines.

OCPs' own high physical activity levels were one of the facilitators in the routine provision of the physical activity recommendation. This finding is consistent with that of previous studiers [19,21,25] where OCPs with higher physical activity levels themselves tended to have positive attitudes to physical activity promotion and provide more physical activity information to patients. Compared with more than $60 \%$ of OCPs not meeting the physical activity recommendations themselves in previous studies [26], our OCPs had higher physical activity levels (57\% of OCPs met the physical activity recommendation), and it is possible that OCPs with a more positive attitude toward physical activity promotion responded, overestimating the impact. Therefore, further research is needed to confirm whether own high physical activity level is a facilitator in the routine provision of the physical activity recommendation.

There were several limitations in this study. The results cannot be generalized to all OCPs. There could have been participation bias because the response rates were low (JBCS: $8.9 \%$ and JACR: 16.4\%) and those who volunteered to participate might have had a strong interest in the physical activity recommendation.

\section{Conclusion}

We clarified that only one fifth of OCPs routinely provide physical activity information and only $19.1 \%$ of them are aware of the detailed contents of the JBCS physical activity recommendation for BCSs in Japan. Barriers to their routine provision of the physical activity recommendation were 1) perception that the recommendation was not within the scope of their work responsibilities, 2) underestimation of survivors' physical activity needs, 3) lack of resources, 4) lack of self-efficacy, and 5) poor knowledge of the recommendation. In addition, the related factors of being aware of the details of the recommendation were 1) availability of the JBCS guidelines at the facility, 2) experience reading the part about epidemiology and diagnosis in the guidelines, and 3) opportunity to discuss survivorship care for survivors in a multidisciplinary team.

Thus, to facilitate implementation of the provision of the physical activity recommendation, we suggest the following actions: 1) disseminate the JBCS revised guidelines to all OCPs, 2) provide education and training programs for OCPs about promoting physical activity, 3) develop institutional resources and/or strengthen collaboration with surrounding resources to help maintain high physical activity levels in BCSs, 4) conduct further research to confirm the benefits of physical activity for BCSs in the Japanese population, and 5) develop programs to help BCSs maintain high physical activity levels that are less costly in terms of time and resources than those currently available. In addition, conducting case meetings in a multidisciplinary team and reviewing evidence-based clinical practice will enhance dissemination and implementation of the guidelines.

Supplementary Information The online version contains supplementary material available at https://doi.org/10.1007/s00520-021-06706-8.

Acknowledgements We are grateful to Professor Shigeru Imoto, President of the JBCS, and Professor Tetsuya Tsuji, President of the JACR, and the members of the associations who helped recruit the participants. We thank all participants in the focus group interviews, which led to the development of the survey items. We also thank Ms. Noriko Watanabe and Dr. Hikaru Ihira for their generous support of the study. We also thank National Center Consortium in Implementation Science for Health Equity (N-EQUITY), funded by the Japan Health Research Promotion Bureau (JH) Research Fund (2019-(1)-4), for providing knowledge on dissemination and implementation research.

Author contribution YS, KT, EO, RO, HI, and YM conceived the study and drafted the original protocol. YS, KT, EO, RO, TS, NS, AK, HI, and YM contributed to developing the survey questionnaire. AK played a major role in statistical analysis. All authors participated in, read, and approved the final manuscript.

Funding This study was supported by a National Cancer Center Research and Development Fund (30-A-17).

Data availability The data that support the findings of this study are available from the corresponding author upon reasonable request.

Code availability Not applicable.

\section{Declarations}

Ethics approval This survey of OCPs did not collect identifying personal information or ask invasive questions. The institutional review board of the National Cancer Center Japan waived the need for ethics review. We conducted the survey with approval from the chair of the National Cancer Center Japan and the academic committee of the 
JBCS. We conducted the survey in accordance with the policies outlined in relevant ethical guidelines such as the Declaration of Helsinki, with due consideration given to the protection of individuals.

Consent to participate Consent to participate was obtained by marking a check box provided with the study prospectus.

Consent for publication All authors consent to publication of this article in Supportive Care in Cancer.

Conflict of interest EO has received research support from Nippon Suisan Kaisha, Ltd. YJM has received speaker fees from Suntory Wellness, Pfizer, Mochida, Eli Lilly, Morinaga Milk, and Cimic and is conducting collaborative research with Susmed. AK has received speaking fees from Chugai Pharmaceutical Co., Ltd. All other authors declare that they have no competing interests regarding this work.

Open Access This article is licensed under a Creative Commons Attribution 4.0 International License, which permits use, sharing, adaptation, distribution and reproduction in any medium or format, as long as you give appropriate credit to the original author(s) and the source, provide a link to the Creative Commons licence, and indicate if changes were made. The images or other third party material in this article are included in the article's Creative Commons licence, unless indicated otherwise in a credit line to the material. If material is not included in the article's Creative Commons licence and your intended use is not permitted by statutory regulation or exceeds the permitted use, you will need to obtain permission directly from the copyright holder. To view a copy of this licence, visit http://creativecommons.org/licenses/by/4.0/.

\section{References}

1. Irwin ML et al (2011) Physical activity and survival in postmenopausal women with breast cancer: results from the women's health initiative. Cancer Prev Res (Phila) 4(4):522-9. https://doi.org/10. 1158/1940-6207.capr-10-0295

2. Holmes MD et al (2009) Physical activity's impact on the association of fat and fiber intake with survival after breast cancer. Am J Epidemiol 170(10):1250-6. https://doi.org/10.1093/aje/kwp291

3. Bertram LA et al (2011) Physical activity, additional breast cancer events, and mortality among early-stage breast cancer survivors: findings from the WHEL Study. Cancer Causes Control 22(3):42735. https://doi.org/10.1007/s10552-010-9714-3

4. Beasley JM et al (2012) Meeting the physical activity guidelines and survival after breast cancer: findings from the after breast cancer pooling project. Breast Cancer Res Treat 131(2):637-43. https:// doi.org/10.1007/s10549-011-1770-1

5. The Japan Breast Cancer Society, 7. Relationship between lifestyle, environmental factors and prognosis of breast cancer patients $C Q 9$. Can we recommend breast cancer patients maintain high levels of physical activity?, in Part of epidemiology and diagnosis. 2018, Kanehara \& Co., Ltd.: Tokyo. p. 144-148.

6. Runowicz CD et al (2016) American Cancer Society/American Society of Clinical Oncology Breast Cancer Survivorship Care Guideline. CA Cancer J Clin 66(1):43-73. https://doi.org/10.3322/ caac. 21319

7. Iwata $\mathrm{H}$ et al (2020) The Japanese Breast Cancer Society Clinical Practice Guidelines, 2018 edition: the tool for shared decision making between doctor and patient. Breast Cancer 27(1):1-3. https:// doi.org/10.1007/s12282-019-01021-x

8. Blanchard CM, Courneya KS, Stein K (2008) Cancer Survivors' Adherence to Lifestyle Behavior Recommendations and
Associations With Health-Related Quality of Life: Results From the American Cancer Society's SCS-II. Journal of Clinical Oncology 26(13):2198-2204. https://doi.org/10.1200/jco.2007.14.6217

9. Bellizzi KM et al (2005) Health behaviors of cancer survivors: examining opportunities for cancer control intervention. J Clin Oncol 23(34):8884-93. https://doi.org/10.1200/jco.2005.02.2343

10. Harrison S, Hayes SC, Newman B (2009) Level of physical activity and characteristics associated with change following breast cancer diagnosis and treatment. Psychooncology 18(4):387-94. https://doi. org/10.1002/pon.1504

11. Hefferon $\mathrm{K}$ et al (2013) Understanding barriers to exercise implementation 5-year post-breast cancer diagnosis: a large-scale qualitative study. Health Educ Res 28(5):843-56. https://doi.org/10.1093/ her/cyt083

12. Charlier $\mathrm{C}$ et al (2013) The contribution of general and cancerrelated variables in explaining physical activity in a breast cancer population 3 weeks to 6 months post-treatment. Psychooncology 22(1):203-11. https://doi.org/10.1002/pon.2079

13. Ottenbacher AJ et al (2011) Exercise among breast and prostate cancer survivors-what are their barriers? J Cancer Surviv 5(4):413-9. https://doi.org/10.1007/s11764-011-0184-8

14. Jones LW, Courneya KS (2002) Exercise counseling and programming preferences of cancer survivors. Cancer Pract 10(4):208-215

15. Demark-Wahnefried W et al (2000) Current health behaviors and readiness to pursue life-style changes among men and women diagnosed with early stage prostate and breast carcinomas. Cancer 88(3):674-684

16. Jones LW et al (2004) Effects of an oncologist's recommendation to exercise on self-reported exercise behavior in newly diagnosed breast cancer survivors: a single-blind, randomized controlled trial. Ann Behav Med 28(2):105-13. https://doi.org/10.1207/s15324796a bm2802_5

17. Winters-Stone KM et al (2018) Enhancing an oncologist's recommendation to exercise to manage fatigue levels in breast cancer patients: a randomized controlled trial. Support Care Cancer 26(3):905-912. https://doi.org/10.1007/s00520-017-3909-z

18. Park JH et al (2015) The effect of oncologists' exercise recommendations on the level of exercise and quality of life in survivors of breast and colorectal cancer: A randomized controlled trial. Cancer 121(16):2740-8. https://doi.org/10.1002/cncr.29400

19. Park JH et al (2015) Characteristics of attitude and recommendation of oncologists toward exercise in South Korea: a cross sectional survey study. BMC Cancer 15:249. https://doi.org/10.1186/ s12885-015-1250-9

20. Jones LW et al (2005) Oncologists' opinions towards recommending exercise to patients with cancer: a Canadian national survey. Support Care Cancer 13(11):929-37. https://doi.org/10.1007/ s00520-005-0805-8

21. Nadler M et al (2017) Oncology care provider perspectives on exercise promotion in people with cancer: an examination of knowledge, practices, barriers, and facilitators. Support Care Cancer 25(7):2297-2304. https://doi.org/10.1007/s00520-017-3640-9

22. Keith RE et al (2017) Using the Consolidated Framework for Implementation Research (CFIR) to produce actionable findings: a rapidcycle evaluation approach to improving implementation. Implementation Science 12(1):15. https://doi.org/10.1186/s13012-017-0550-7

23. Damschroder, L.J., et al., Fostering implementation of health services research findings into practice: a consolidated framework for advancing implementation science. Implement Sci, 2009. 4: https://doi.org/10.1186/1748-5908-4-50.

24. Connell LA et al (2014) Therapists' use of the Graded Repetitive Arm Supplementary Program (GRASP) intervention: a practice implementation survey study. Phys Ther 94(5):632-43. https://doi. org/10.2522/ptj.20130240

25. Hardcastle SJ et al (2018) Knowledge, attitudes, and practice of oncologists and oncology health care providers in promoting 
physical activity to cancer survivors: an international survey. Support Care Cancer 26(11):3711-3719. https://doi.org/10.1007/ S00520-018-4230-1

26. Alderman G et al (2020) Health Care Professionals' Knowledge and Attitudes Toward Physical Activity in Cancer Patients: A Systematic Review. Seminars in Oncology Nursing 36(5):151070. https:// doi.org/10.1016/j.soncn.2020.151070

27. Fujii $\mathrm{H}$ et al (2011) Validity and applicability of a simple questionnaire for the estimation of total and domain-specific physical activity. Diabetology International 2(2):47-54. https://doi.org/10. 1007/s13340-011-0025-z

28. Sasai H et al (2018) Simultaneous Validation of Seven Physical Activity Questionnaires Used in Japanese Cohorts for Estimating Energy Expenditure: A Doubly Labeled Water Study. Journal of Epidemiology 28(10):437-442. https://doi.org/10.2188/jea.JE20170129

29. Ministry of Health, Labour and Welfare. "Physical activity standards for health in 2013" and "Physical activity guidelines for health ('active guide')" ("Healthy Japan 21"). 2013 [cited 2021 March 19th]; Available from: https://www.mhlw.go.jp/stf/houdou/2r985 2000002xple.html.

30. Shimizu Y et al (2020) Study protocol for a nationwide questionnaire survey of physical activity among breast cancer survivors in Japan. BMJ Open 10(1):e032871. https://doi.org/10.1136/bmjop en-2019-032871

31. Tsuji K et al (2019) Effect of home-based high-intensity interval training and behavioural modification using information and communication technology on cardiorespiratory fitness and exercise habits among sedentary breast cancer survivors: habit-B study protocol for a randomised controlled trial. BMJ Open 9(8):e030911. https://doi.org/10.1136/bmjopen-2019-030911

32. Ochi E et al (2021) Cardiorespiratory fitness in breast cancer survivors: a randomised controlled trial of home-based smartphone supported high intensity interval training. BMJ Support Palliat Care. https://doi.org/10.1136/bmjspcare-2021-003141:10.1136/ bmjspcare-2021-003141

33. Bandura A (1988) Self-efficacy conception of anxiety. Anxiety Research 1(2):77-98. https://doi.org/10.1080/10615808808248222

34. Maddux JE, Sherer M, Rogers RW (1982) Self-efficacy expectancy and outcome expectancy: Their relationship and their effects on behavioral intentions. Cognitive Therapy and Research 6(2):207211. https://doi.org/10.1007/BF01183893

35. Schmitz KH et al (2019) Exercise is medicine in oncology: Engaging clinicians to help patients move through cancer. CA Cancer J Clin 69(6):468-484. https://doi.org/10.3322/caac.21579

36. Senauer, B. and M. Gemma, Why Is the Obesity Rate So Low in Japan and High in the U.S.? Some Possible Economic Explanations. 2006.

37. Stemmermann GN (1991) The pathology of breast cancer in Japanese women compared to other ethnic groups: a review. Breast Cancer Res Treat 18(Suppl 1):S67-72. https://doi.org/10.1007/bf026 33531

38. Han $\mathrm{Y}$ et al (2019) Do breast quadrants explain racial disparities in breast cancer outcomes? Cancer Causes Control 30(11):1171-1182. https://doi.org/10.1007/s10552-019-01222-x

Publisher's note Springer Nature remains neutral with regard to jurisdictional claims in published maps and institutional affiliations.

\section{Authors and Affiliations}

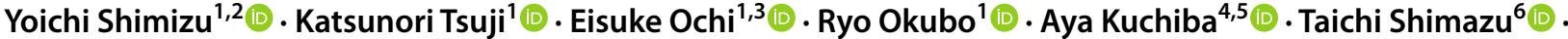 Noriatsu Tatematsu ${ }^{7} \cdot$ Naomi Sakurai $^{8} \cdot$ Hiroji Iwata $^{9}$ - Yutaka J. Matsuoka ${ }^{1,10} \mathbb{C}_{\mathbb{D}}$}

\author{
Yoichi Shimizu \\ yoshimiz@ncc.go.jp \\ Katsunori Tsuji \\ ktsuji@ncc.go.jp \\ Eisuke Ochi \\ ochi@hosei.ac.jp \\ Ryo Okubo \\ ryo-okubo@ncnp.go.jp \\ Aya Kuchiba \\ akuchiba@ncc.go.jp \\ Taichi Shimazu \\ tshimazu@ncc.go.jp \\ Noriatsu Tatematsu \\ tatematsu@met.nagoya-u.ac.jp \\ Naomi Sakurai \\ sakurai@cansol.jp \\ Hiroji Iwata \\ hiwata@aichi-cc.jp
}

1 Division of Health Care Research, Center for Public Health Sciences, National Cancer Center Japan, 5-1-1 Tsukiji, Chuo-ku, Tokyo 104-0045, Japan
2 Department of Nursing, National Cancer Center Hospital, Tokyo, Japan

3 Faculty of Bioscience and Applied Chemistry, Hosei University, Tokyo, Japan

4 Division of Biostatistical Research, Center for Public Health Sciences/Biostatistics Division, Center for Research Administration and Support, National Cancer Center Japan, Tokyo, Japan

5 Graduate School of Health Innovation, Kanagawa University of Human Services, Kanagawa, Japan

6 Division of Behavioral Sciences, Center for Public Health Sciences, National Cancer Center Japan, Tokyo, Japan

7 Department of Integrated Health Sciences, Graduate School of Medicine, Nagoya University, Nagoya, Japan

8 Cancer Solutions Inc, Tokyo, Japan

9 Department of Breast Oncology, Aichi Cancer Center Hospital, Nagoya, Japan

10 Lifestyle Medicine, Cooperative Graduate Program, The Jikei University Graduate School of Medicine, Tokyo, Japan 